\title{
Thermo-energetic analysis and simulation of the fluidic cooling system of motorized high-speed spindles
}

\author{
Juliane Weber, and Jürgen Weber \\ Institute of Fluid Power, Dresden University of Technology, 01062 Dresden, Germany \\ E-mail: juweber@ifd.mw.tu-dresden.de, weber@ifd.mw.tu-dresden.de
}

\begin{abstract}
Beside drive tasks for feeding movements and tool clamping, fluid power systems especially permit the temperature control in machine tools: They allow cooling or pre-heating of both single components and complete assemblies (e.g. frame components, drive motors and spindles). In this respect, fluid power systems are an important element for controlling and managing the thermo-elastic behaviour of machine tools. As an essential part of the machine, they must be included from the beginning of the design studies of machine tools - particularly in terms of accuracy under conditions of energy-efficient manufacturing.

The increasing complexity and performance of fluid power systems generally lead to an increased use of auxiliary power. This has to be critically examined from an economic and environmental point of view. Focusing especially on the optimum thermal performance with minimum power supply, existing simulation models are not adequate for a scientifically based design. The complex system structures as well as the lack of basic investigations and design tools lead to a thermal optimization problem that is not solved satisfactorily today. For this purpose the Institute of Fluid Power (IFD) develops principles and simulation models with a holistic approach.

Based on the analysis of general tooling machines fluidic subsystems are identified and essential modelling requirements are specified. From a fluid-technical perspective the motor spindle represents an important principal component, and therefore, is a particular focus of current investigations. Starting from the basic technical structure of the motor spindles an abstract model is derived. This model represents the basis for different simulation strategies such as network-based or numerical ones. To study the thermal behaviour of cooling sleeves in motor spindles - especially with regard to the parameter identification and the validation of simulation models - a test rig was developed. The modular construction of the test rig ensures a simple replacement of the cooling sleeve allowing the examination of different flow geometries.
\end{abstract}

Keywords: heat transfer, high-speed spindle, numerical simulation, network-based simulation 


\section{Introduction}

In machine tools, a variety of fluid power systems are used such as pumps, heat exchanger or cooling components in motors and spindles (see fig. 1). Beside drive tasks for feeding movements and tool clamping, they especially facilitate the temperature control in machine tools. In this respect, fluid power systems are an important element for controlling and managing the thermo-elastic behaviour of machine tools.

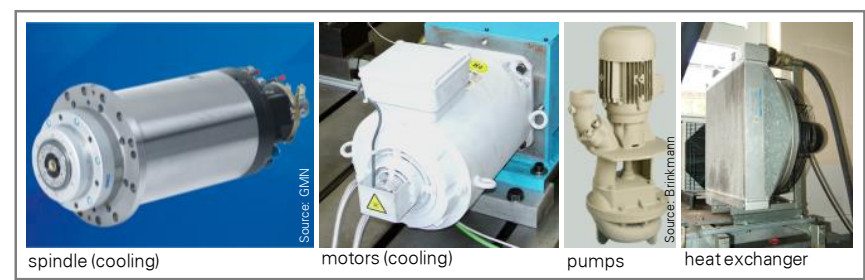

Figure 1: Examples of important fluid power components in machine tools.

The working precision of cutting machine tools depends to a significant degree on the relative motion between the workpiece and the tool. Machine disturbances such as temperature gradients occurring in the feed units and the working spindle limit the overall precision, both dimensional and geometrical, and the surface quality of the machined workpiece. For example, heat losses in the bearings and the motor of the working spindle result in reduced bearing stiffness and thermal deformations. This causes a displacement of the tool centre point (TCP) and, consequently, has a negative effect on the production quality. Thus, knowledge of the sources of losses, the heat flow paths and the resulting temperature distribution in motor spindles or feed units represents an essential basis for the characterization of the thermal behaviour of these main components - aiming at the improvement of the manufacturing quality and the process.

To reduce the displacement of the TCP fluid-technical spindle cooling systems are used. The cooling liquid circuit is realized by a cooling jacket or by directly flowing through the spindle shaft [1]. In [2] cooling systems with helical channel structures were examined. The main focus was to increase the efficiency by adjusting the channel slope and width. Cooling the spindle can also be realized by means of a heat pipe [3]. By local evaporation and condensation of a fluid within a closed volume this element allows an efficient evacuation of heat. With the aim of enhancing the displacement of the spindle and the life cycle of spindle bearings, Gebert developed an approach describing the thermal processes occurring in high-frequency spindle motor systems [4]. In [5] the heat transfer in high-speed spindle housings with helical cooling channels is analyzed. By numerical simulations the temperature distribution in the fluid flow was determined and experimentally verified.

The purpose of this paper is to develop a network-based computation model that describes the transient, threedimensional energy exchanging processes in built-in motorized spindles - especially in a cooling sleeve with a single helical rectangular water-cooling channel (see variant d in fig. 4). Since tool machines are high-precision plants, an outstanding level of accuracy is required for the thermoenergetic calculation. Regarding future combinations of component models for the description of complete system structures the network-based model benefits from less modelling effort and computation time.

\section{Methodology and modelling approach}

The aim of the research activities is the development of system-describing thermo-fluidal models. Therefore the modelling approach is divided in four parts: The experimental investigation of systems and of components as well as the development of numerical and network-based simulation models - as depicted in fig. 2.

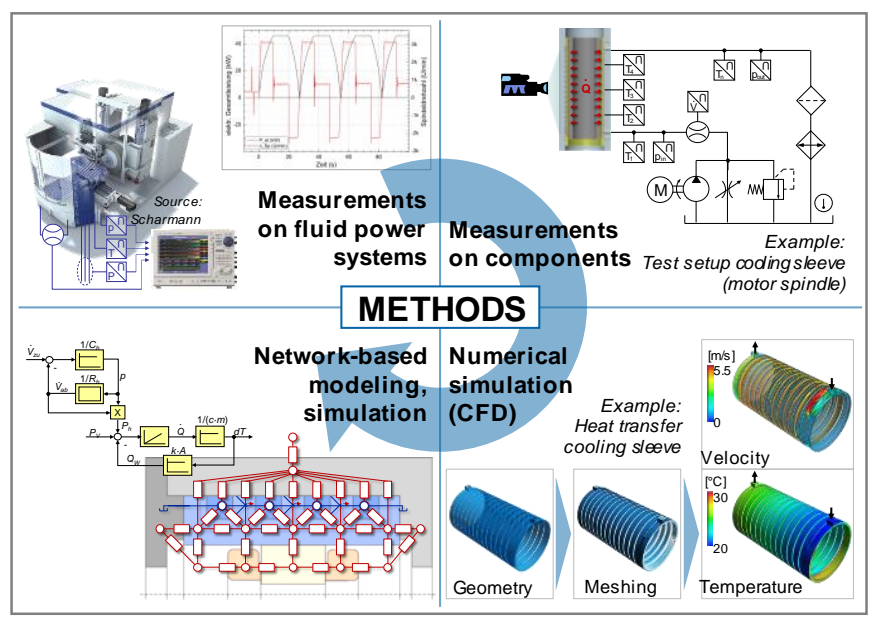

Figure 2: Overview of the methodology for the development of holistic fluidic simulation models.

In the first step fluid technical cooling systems are investigated experimentally in the tooling machine directly. On this basis, information concerning the physical active structures and the machine operations are received. Thus, the crucial main components are identified. Secondly, these main components have to be analyzed experimentally. The aim is to extract key figures and reference variables for the simulation models from these measurement data. The development of thermo-energetic component models with help of network-based modelling techniques starts with the analysis of existing simulation tools and the identification of the specific modelling requirements. Subsequently, extensive numerical simulations (CFD) are carried out in the third step. These simulations make the thermo-energetic exchange processes visible in a high temporal and spatial resolution, even inside the components. They support significantly the derivation of structures as well as parameters for the network modelling and represent an additional basis for comparison beside the measured data. Within the last step abstract component models are derived by the use of network-based modelling techniques. In contrast to numerical models they promote a fast calculation, even on lower performance machines. Consequently it is of great advantage to combine single component models to whole system describing models. Thus, the acting physical relationships and interactions 
between the components can be characterized precisely at the system level. To check the suitability of component models for the precise calculation of the real system and to exclude an unacceptable adding up of individual errors, a further verification using measurement data is necessary.

In this paper, the development of a network-based simulation model is illustrated - especially for the stator cooling sleeve of a motorized high-speed spindle. Therefore, the focus is on the experimental investigations as well as the numerical simulation model used for the extraction of important key figures and reference data.

\section{Design of motorized high-speed spindles}

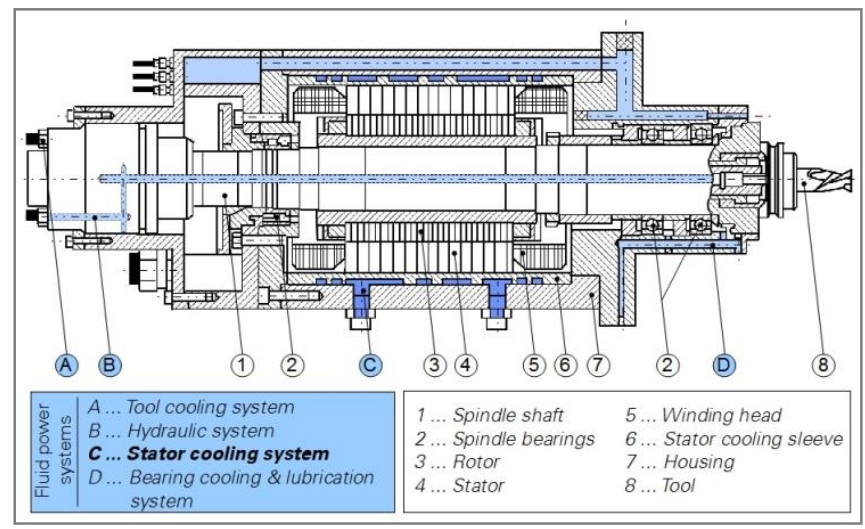

Figure 3: Principle structure of a motor spindle, adapted from [4].

Motor spindles are specifically used in high-speed cutting (HSC) machining centres and milling machines. As a result of the rapid tool rotation high centrifugal forces occur and thus power transmission devices such as belts or gears cannot be utilized. Consequently, the spindle is directly driven by a built-in motor. Figure 3 illustrates the basic structure of a built-in motorized spindle with a helical rectangular water-cooling channel. The main fluid systems are highlighted in blue. The hydraulic system (B) serves for the tool clamping. The cooling system can be divided regarding the components that needed to be cooled: the tool (A), the stator (C) and the bearings (D).
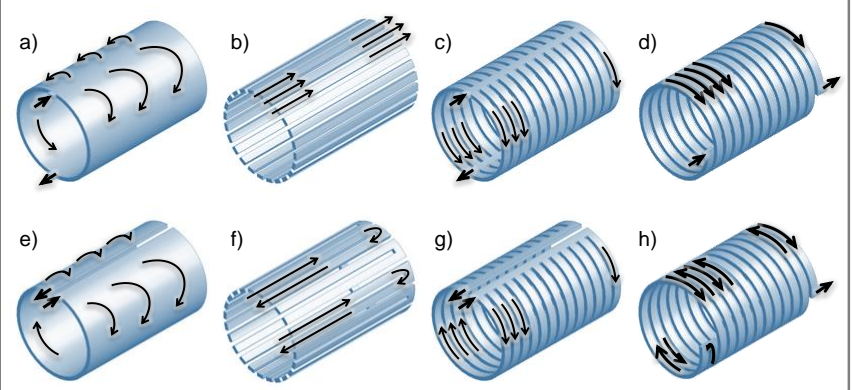

Figure 4: Typical types of flow geometries within the stator cooling sleeve.

Hence, one subject of current research is the cooling of the motor - especially the stator - via a cooling sleeve. This cooling sleeve is press-fitted into the stator and a cooling liquid flows around its outer radius. The sleeve itself is made of a highly thermally conductive material (e.g. brass), and may additionally comprise rib structures at the outer radius improving the heat transfer into the fluid. In Figure typical flow paths resulting from different geometries of the cooling sleeve are depicted, where the single helical and the double helical channel structure (variants $\mathrm{d}$ and $\mathrm{h}$ ) are the most common ones [4]. The current research focuses on the single helical channel variant $d$.

\section{Experimental test set-up}

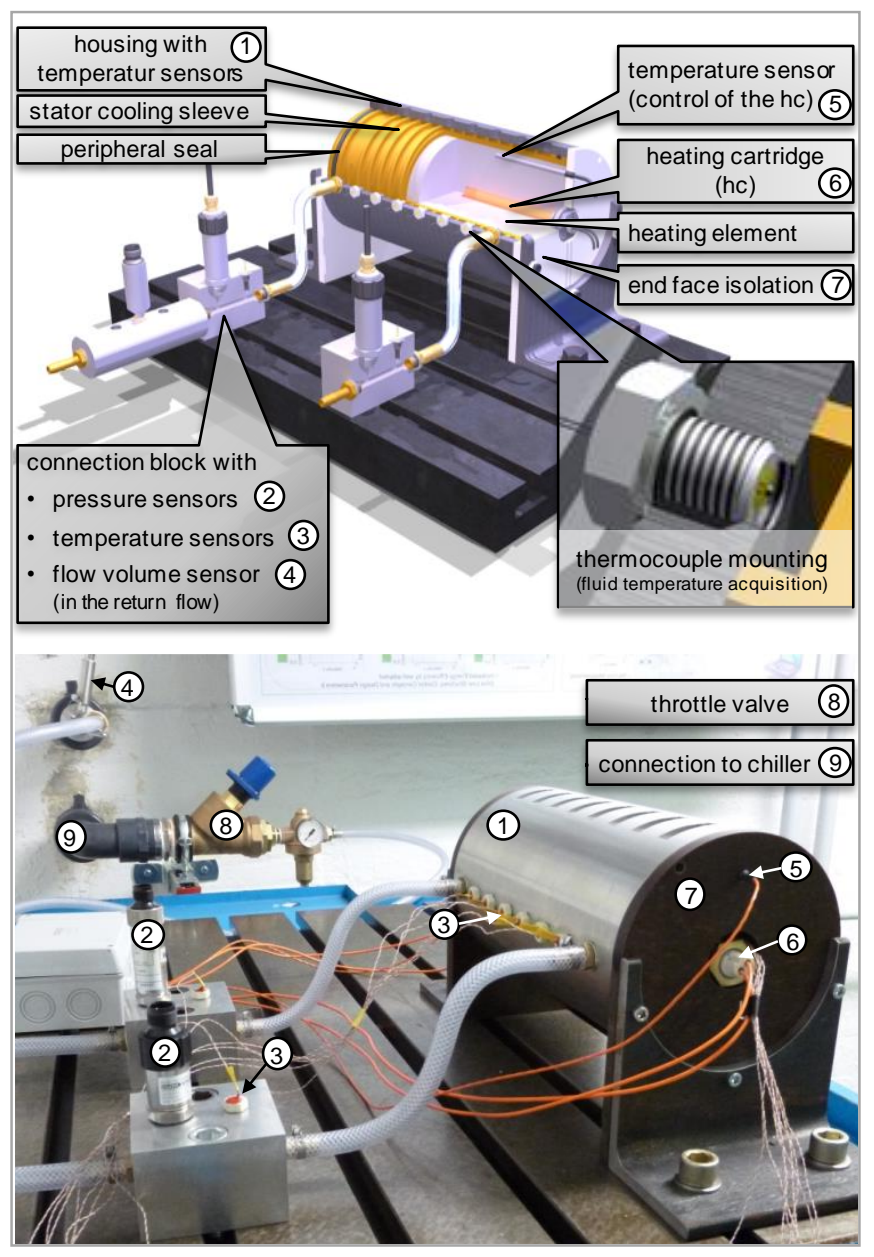

Figure 5: CAD model and real experimental set-up for the investigation of the thermal behaviour of stator cooling sleeves with different flow geometries.

A test stand (see fig. 5) has been developed allowing measurement of both fluid and surface temperatures of the stator cooling sleeves under defined conditions. In parallel, the upstream and downstream pressure as well as the throttle flow rate is measured. The modular design of the test stand permits a simple replacement of the cooling sleeve to examine different flow geometries in detail. The energy input into the cooling sleeve is realized due to two heating cartridges centrally introduced into an aluminium cylinder whose power can be controlled separately. The temperature is locally measured at defined intervals in the axial direction at the inner wall of the cooling sleeve, on the housing wall 
and in the fluid. They mainly depend on the supplied amount of heat, the flow rate and the composition of the cooling liquid. In addition, an infrared camera is used for an area-wise detection of the temperature of the housing surface and the investigation of the temperature distribution.

First measurements were done with chilled water as working medium in the helical channel. The inlet temperature was set to $20^{\circ} \mathrm{C}$ and controlled by the temperature sensor integrated in the chiller. The fluid temperatures were measured by 8 thermocouples embedded in the helical channel along the axial direction, including the inlet and outlet temperatures. The used thermocouple type was $\mathrm{T}$ with a class 1 calibration, so that the minimum accuracy was within $\pm 0.5 \mathrm{~K}$. The volumetric flow rate was measured by a turbine flow meter with an accuracy within $\pm 0.5 \%$ FS. Furthermore, the pressure was measured in the flow and return flow pipes. The accuracy of the installed electronic pressure transmitters was within $\pm 0.123 \% \mathrm{FS}$. All signals were connected to a junction terminal block and recorded by a NI M Series multifunction data acquisition device.

\section{Modelling and simulation}

\subsection{Basic concepts of modelling}

Figure 6 illustrates the flow diagram of a fluid-technical component model, whereby the investigation scope is strictly limited to the component's inner wall. The focus is on network-based computing models. The input parameters (e.g. flow rate, wall temperature, and thermal conductivity) characterize the thermal behaviour and the flow, and are directly ascertained from existing design and material data, numerical simulations or experimental studies. The results of the network-based calculation are for instance the transferred heat flux, the fluid temperature and the amount of auxiliary energy required for driving the flow.

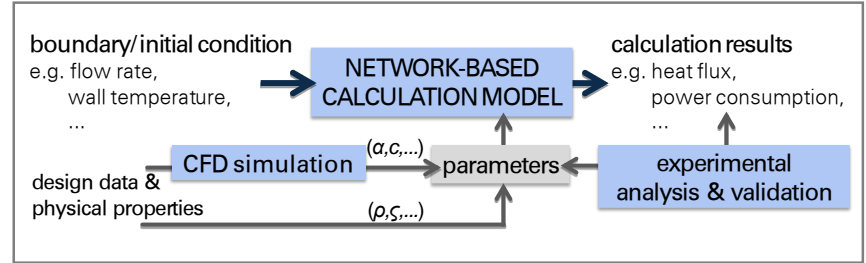

Figure 6: Flow of information within a fluid-technical component model.

In table 1 the basic dynamic relationships of hydraulics, pneumatics, thermodynamics, mechanics and electric engineering are depicted. The behaviour of systems of various types of energy is describable in the same way using these basic dynamic relationships. They form the basis for a cross-system simulation in a computational model.

Furthermore, the figure shows a categorization of the basic dynamic relationships of various forms of energy with respect to the calculation of flow and potential variables. On this basis, the basic relationships are attributed to nodes and elements. The potential variable is calculated in a node from the sum of the flow variables. The flow variable is determined by the difference of potential variables at the element.

The model structure is basically set up in alternating arrangement, because of the correlation between the input and output variables of nodes and elements. Due to the summation of the flow variables in the node, any number of elements can be connected to a node. However, at each connection of an element only one node can be located. Thus, the nodes are used to extend the scope of the model and to structure the network-based system or component model. $[6,7,8]$

\section{Table 1: Analogy of basic dynamic elements, adapted from $[6,7,8]$}

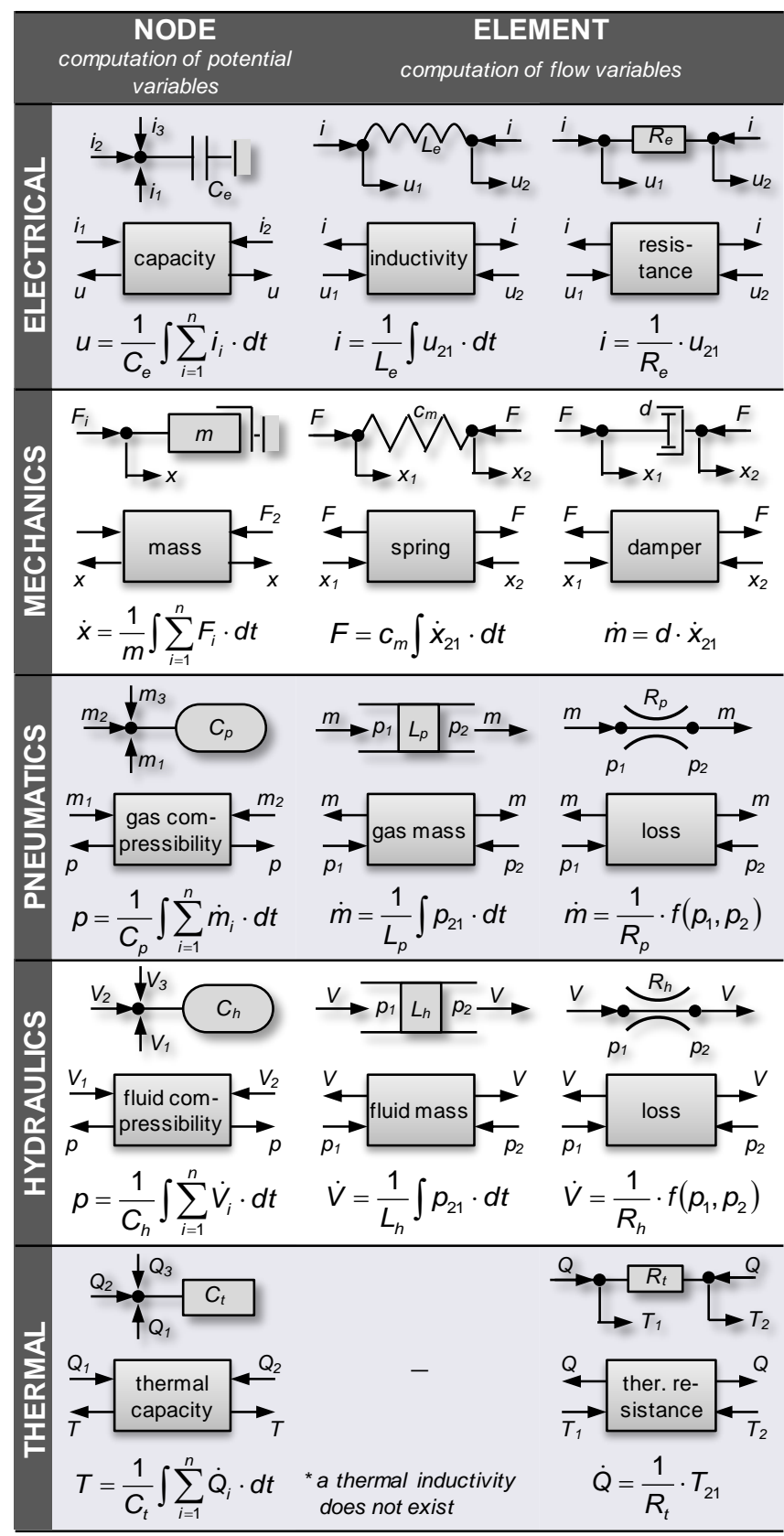

Figure 7 shows a simple example of a network-based model using the basic hydraulic and thermal elements described in 
the table above. The mass or volume is concentrated in the node which is defined by the thermal and/or hydraulic capacity. The nodes are connected to one another via thermal or hydraulic resistances. The input and output parameters of each element as well as the appropriate calculation formulas are depicted in the figure.

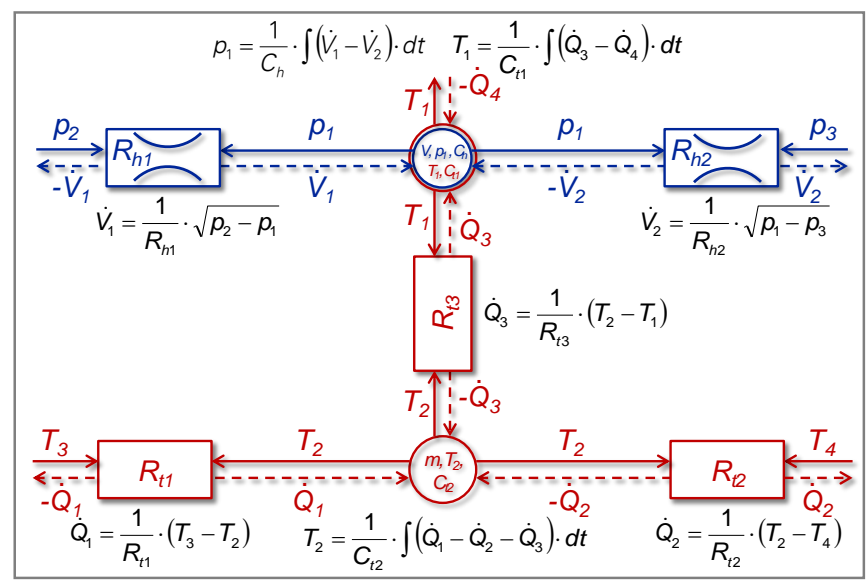

Figure 7: Mathematical description of the basic hydraulic and thermal elements used in a network-based model.

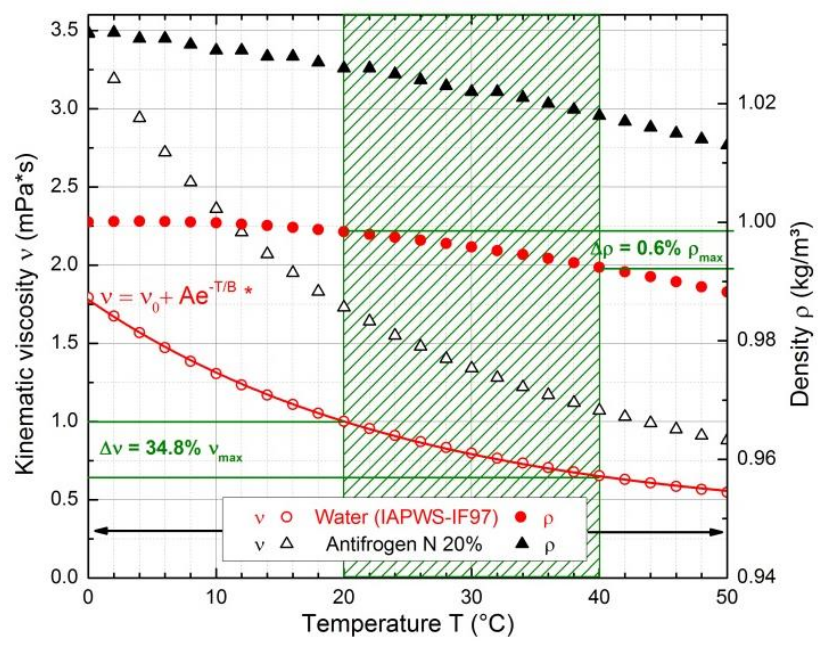

Figure 8: Selection of temperature dependent fluid properties for water and Antifrogen $® N$.

Figure 8 shows a selection of temperature dependent fluid parameters for water and a typical water-glycol-mixture. It can be seen exemplarily for water that the density only changes slightly in the temperature range of interest from 20 to $40^{\circ} \mathrm{C}$. Since the density only changes by $0.6 \%$ the temperature dependency is negligible. On the other hand the kinematic viscosity changes by $34.8 \%$ in the same temperature range and has to be considered in the simulation models. This can be done by implementing the ascertained expression

$$
v=v_{0}+A \cdot e^{-\frac{T}{B}}
$$

with the fitting parameters

$$
v_{0}=0.36 \mathrm{mPa} \cdot \mathrm{s}
$$

$$
\begin{gathered}
A=1.41 \mathrm{mPa} \cdot \mathrm{s} \\
B=25.4^{\circ} \mathrm{C} .
\end{gathered}
$$

A similar approach can be used to extract the relevant parameters for Antifrogen ${ }^{\circledR} \mathrm{N}$ and all other cooling fluids. Furthermore the following assumptions are made to simplify the modelling:

- The thermal capacity and the density of the fluid are temperature independent, whereas the temperature dependency of kinematic viscosity has to be considered.

- The physical properties of the solids (heating element, cooling sleeve, housing, isolation and mounting) are assumed to be isotropic and temperature independent.

- The flow is considered to be steady and turbulent with no viscous dissipation.

- Gravity and buoyancy effects are neglected.

\subsection{Numerical simulation model and parameter identification}

The development of a numerical simulation model of the stator cooling sleeve is a first approach for the characterization of its thermo-energetic behaviour and its flow as well as the determination of required model parameters. For this purpose the shear stress transport formulation (SST model) was used.

Turbulence models are used to approximate the effects of turbulence without resolving the smallest turbulent fluctuations. The SST model is one of various turbulence models based on the Reynolds Averaged Navier-Stokes (RANS) equations. The SST model is a hybrid two-equation eddy-viscosity model that combines the advantages of both the k- $\omega$ and k- $\varepsilon$ model. Since the advantage of the near wall treatment for low Reynolds number computations the $\mathrm{k}-\omega$ model performs much better for boundary layers. Therefore, computations are more accurate and robust. However, the common $\mathrm{k}-\omega$ problem is its strong sensitivity to the inlet free-stream turbulence properties, while the $\mathrm{k}-\varepsilon$ model is not susceptible to such problems. To overcome this drawback the SST model switches between the k- $\omega$ model near the surface and the k- $\varepsilon$ model in the outer region. Accordingly, in free shear flows the SST model is identical with the $\mathrm{k}-\varepsilon$ model. The SST model is recommended for applications that require a high accuracy in the boundary layer, whereby the minimum resolution is 10 cells. Thus, an automatic nearwall treatment method is applied to model the flow near the wall. The near wall region can be subdivided into two layers. In the innermost, the laminar (viscous) sublayer the viscosity plays a major role in momentum and heat transfer. Further away from the wall, in the logarithmic layer the mixing process is dominated by turbulence. The region between the laminar sublayer and the logarithmic layer is called buffer layer. Effects of molecular viscosity and turbulence are of equal importance here. For more information on the solver and modelling theory, refer to $[9$, $10,11]$. 
To predict the temperature throughout the flow heat transfer has to be taken into account. The heat transfer in the fluid domain is ascertained by the energy transport equation

$$
\frac{\partial\left(\rho h_{t o t}\right)}{\partial t}-\frac{\partial p}{\partial t}+\nabla\left(\rho U h_{t o t}\right)=\nabla(\lambda \nabla T)+\nabla(U \cdot \tau)+S_{E}
$$

Since the flow is considered to be steady and the viscous dissipation is neglected the expression can be simplified

$$
\nabla\left(\rho U h_{t o t}\right)=\nabla(\lambda \nabla T)+S_{E} .
$$

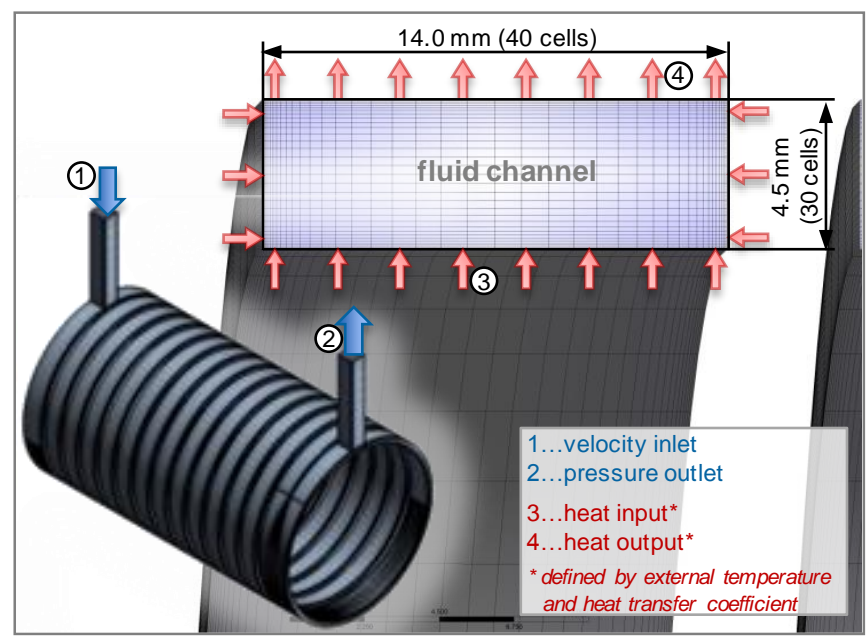

Figure 9: Fluid volume's total grid and cross-section through one turn of the helical channel.

Figure 9 shows the discretized fluid volume that is used in the computational domain. The grid comprises up to around 2.097 million hexahedral elements where the minimum quality of the elements is 0.66 and the mean quality 0.97 . The grid is structured and was generated by using the blocking method and edge bunching laws in ANSYS ICEM. To minimize the computing time disparate time-scales of heat transfer and fluid flow are utilized. The computations are performed in parallel on four cores and lasted about eight hours until residuals of all the variables were less than $1.0 \times 10^{-5}$.

Since the heat transfer in the solids is actually not considered in the numerical simulation it is necessary to specify a so-called alternative heat transfer coefficient $\alpha_{\text {alt }}$ in relation to the fluid temperature difference $\Delta \mathrm{T}_{\mathrm{F}}$ between the inlet and outlet. This coefficient describes the heat transfer consisting of the heat transfer between the heating element, the cooling sleeve and the fluid as well as the heat conduction in the heating element and the cooling sleeve. In order to identify this alternative heat transfer coefficient $\alpha_{\text {alt }}$ several simulations were performed. In fig. 10 the characteristic map of $\alpha_{\text {alt }}$ as a function of the fluidic temperature difference $\Delta T_{F}$ is depicted for varying volume flow rates $(5 \mathrm{l} / \mathrm{min}, 10 \mathrm{l} / \mathrm{min}$ and $14 \mathrm{l} / \mathrm{min})$ and two constant temperatures $T_{H}$ in the heating element $\left(30^{\circ} \mathrm{C}\right.$ and $\left.40^{\circ} \mathrm{C}\right)$.

By analogy, the cooling capacity $P_{Q}$ of the fluid depending on the fluids temperature difference $\Delta T_{F}$ is determined by several numerical simulations. Its characteristic map is shown in fig. 11.

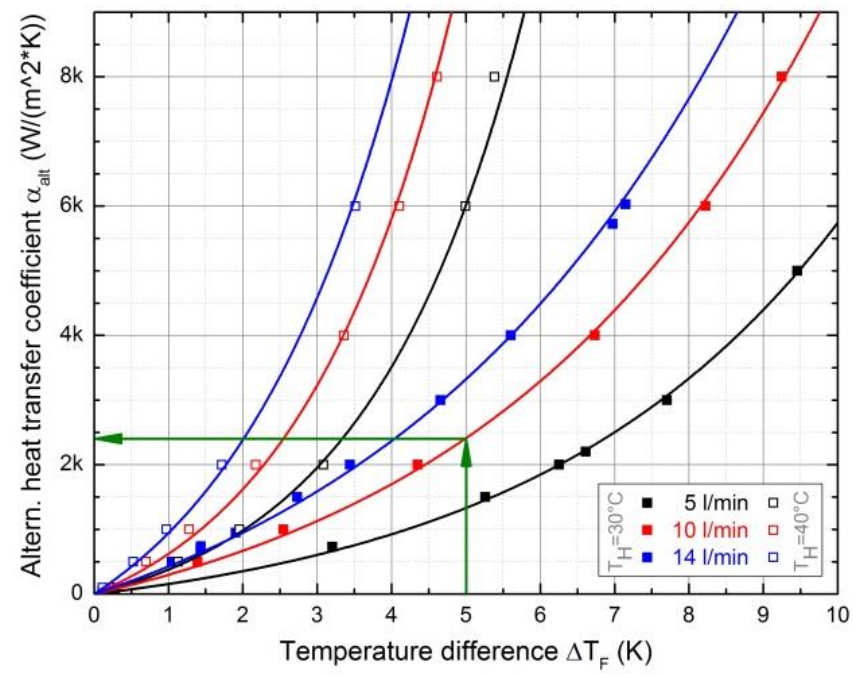

Figure 10: Alternative heat transfer coefficient $\alpha_{a l t}$ depending on the fluid temperature difference $\Delta T_{F}$ between inlet and outlet.

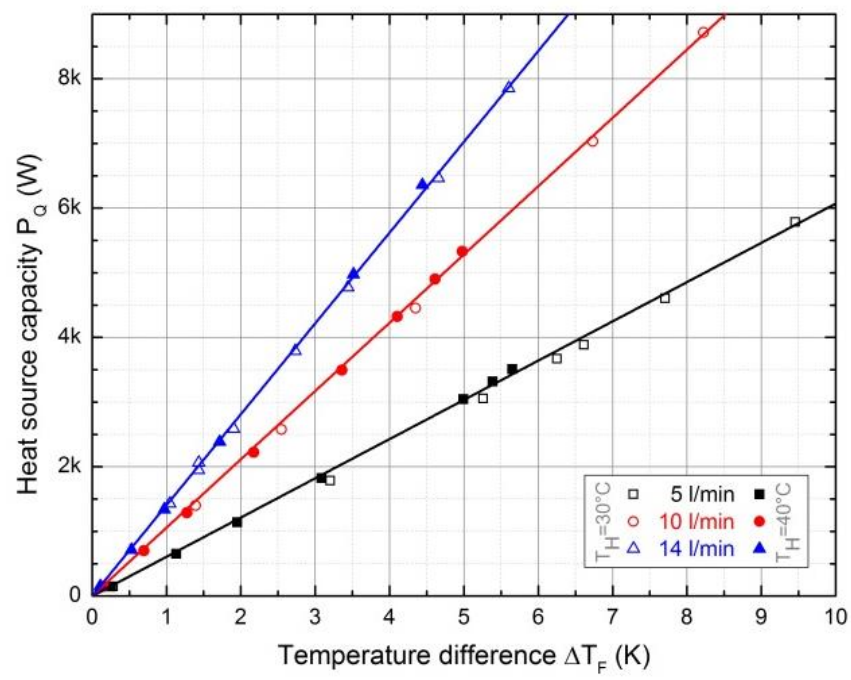

Figure 11: Cooling capacity $P_{Q}$ depending on the fluid temperature difference $\Delta T_{F}$ between inlet and outlet.

\subsection{Network-based simulation}

Simulation models based on concentrated parameters feature a wide range of interfaces to external CAx- and database programs, and short computing times with resulting cost savings. Therefore, the applicability of existing modelling tools (like SimulationX) is examined for the description of a real component. As can be seen from fig. 12, the networkbased model of a cooling system for motor spindles is composed of blocks describing the physical correlations of single elements. The potentials required for the computation are transported by thermal or hydraulic connections between the individual blocks. The overall model consists of geometrically simple subcomponents whose behaviour can 
be described by general equations of thermodynamics and fluid power $[11,12,13,14]$.

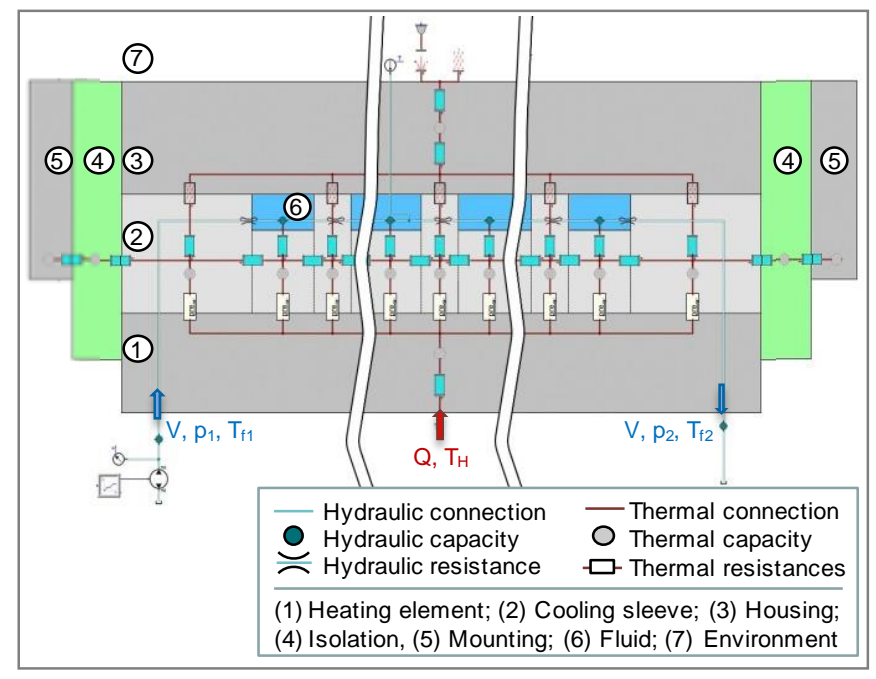

Figure 12: Network-based simulation model of the stator cooling sleeve according to the test set-up.

The power dissipation of the motor spindle is either represented by a heat input or by a fixed temperature that is higher than the ambient temperature. The difference between the induced and ambient temperature causes a heat flow in the system. This heat flow is transported through the model of the cooling system by heat conduction in the parts and heat transfer between the parts. The heat transport essentially propagates through cylindrical layers. The used blocks describe the physical correlations of heat conduction and heat transfer with thermal resistances.

$$
\begin{gathered}
R_{t}=\frac{\ln \left(d_{o} / d_{i}\right)}{(2 \pi-\varphi) \cdot l \cdot \lambda} \\
R_{t}=R_{\text {contact }}
\end{gathered}
$$

It is especially challenging to compute the thermal resistances of heat transfer between two solids (i.e. between the heating element and the cooling sleeve), because the modelling of the contact points is afflicted with some degree of uncertainty. Due to a comparison of the computational results with the experimental results this uncertainty may be reduced. The thermal capacities describe the characteristic heating of the solids due to heat supply.

The central process in the simulation of the cooling system is the forced convection of the heat due to the fluids motion. In this context the two disciplines thermodynamics and fluid power mutually influence each other.

The flow through the cooling channel, embedded in a cooling sleeve, exhibit a constant volume flow rate. Moreover, the cooling channel is subdivided into multiple parts and represented by hydraulic capacities in the model. An individual element corresponds to exactly one turn of the helical channel. Here, the model is simplified to describe the complex geometry of the cooling channel at the inlet and the outlet with the available tools. Hence, the slope of the helical cooling channel is neglected, whereby the real heat exchanging surface coincides with the surface in the model. The flow rate is adapted with the help of a correction factor so that the flow conditions are not influenced by the neglected slope. Throttle resistances are located between the hydraulic capacities to describe the resulting pressure drop. The heat transfer from the solid into the cooling fluid is taken into account by the hydraulic capacity with the following relation.

$$
R_{t}=\frac{1}{\alpha \cdot \pi \cdot d \cdot l}
$$

The heat transfer coefficient $\alpha$ is characterized by the dimensionless quantities $\mathrm{Nu}, \mathrm{Re}$ and $\mathrm{Pr}$ of the flow and has a major influence on the heat resistance. The model delivers the possibility to compute laminar as well as turbulent flows. The transition zone between turbulent and laminar is interpolated, so that all flow conditions are possible. The part of the heat flow that is not absorbed by the fluid is transferred to the environment by free convection and heat radiation.

Due to an external database link, the network-based model provides a uniform and clear parameterization, based on the geometry of the cooling system and the physical properties.

The parameterization of the heat transfers coefficients between two solids and the parameterization of forced convection are a great challenge within the modelling of cooling systems of motorized spindles with network-based models. Therefore, it is necessary to compare and optimize these computation models with experimental measurements.

\section{Results and discussion}

In fig. 13a-c the numerical results of the pressure, the velocity and the temperature distribution along the fluids flow path with a heating element temperature $T_{H}=40^{\circ} \mathrm{C}$, a flow rate $\dot{V}=14 \mathrm{l} / \mathrm{min}$ and a fluid inlet temperature $T_{f 1}=20^{\circ} \mathrm{C}$ are presented. The inlet and outlet ports are attached at opposite ends of the spindle housing because the helical channel structure only consists of one pass. Due to production requirements the inlet and outlet channel (see fig. 13 position 1 and 8 , respectively) differ in size and geometry from the other helical channels. These geometrical features are taken into account in the numerical and network-based model as well, in order to achieve a good congruence between experimental data and simulation results. It is obvious from fig. 13 that the almost 180-degree turnaround at the inlet channel causes a necking of the flow. This leads to an increased velocity of about $7 \mathrm{~m} / \mathrm{s}$ accompanied by a pressure drop of about 0.5 bar at the same position. Due to the larger cross section at the inlet and outlet channel the velocity is kept slightly lower than the average velocity of about $4.1 \mathrm{~m} / \mathrm{s}$ in the other helical channels (see fig. 13b). Except the deviations in the inlet and outlet region the fluid velocity distributions are mixed well and become nearly uniform. Furthermore, it can be seen from fig. 13c that the fluid temperature is constantly increasing in the axial direction from the inlet to the outlet. 
Figure 14a depicts the calculated and measured average temperatures of the fluid along the spindle axis with different values of the volume flow rate of $\dot{V}=5 \mathrm{l} / \mathrm{min}$, $10 \mathrm{l} / \mathrm{min}$ and $14 \mathrm{l} / \mathrm{min}$, and with a constant heating element temperature of $T_{H}=40^{\circ} \mathrm{C}$. As expected, the fluid temperature is decreased as the volume flow rate is increased. Since the fluid temperature is increasing along the spindle axis the maximum temperatures are reached at the outlet region. The averaged maximum temperatures at the outlet are $21.6^{\circ} \mathrm{C}, 22.2^{\circ} \mathrm{C}$ and $23.5^{\circ} \mathrm{C}$ for $\dot{V}=14 \mathrm{l} / \mathrm{min}$, $10 \mathrm{l} / \mathrm{min}$ and $5 \mathrm{l} / \mathrm{min}$. Controlled by a chiller, the fluid inlet temperature was fixed at $20^{\circ} \mathrm{C}$. Thus, the temperature differences are $1.5 \mathrm{~K}, 2.2 \mathrm{~K}$ and $3.5 \mathrm{~K}$ for $\dot{V}=14 \mathrm{l} / \mathrm{min}$, $10 \mathrm{l} / \mathrm{min}$ and $5 \mathrm{l} / \mathrm{min}$. In this respect it is noted that the temperature accuracy of the used chiller was within $\pm 0.5 \mathrm{~K}$. This can also be seen in fig. 14, where the inlet temperature differs by $-0.5 \mathrm{~K}$ for a volume flow rate of $5 \mathrm{l} / \mathrm{min}$.

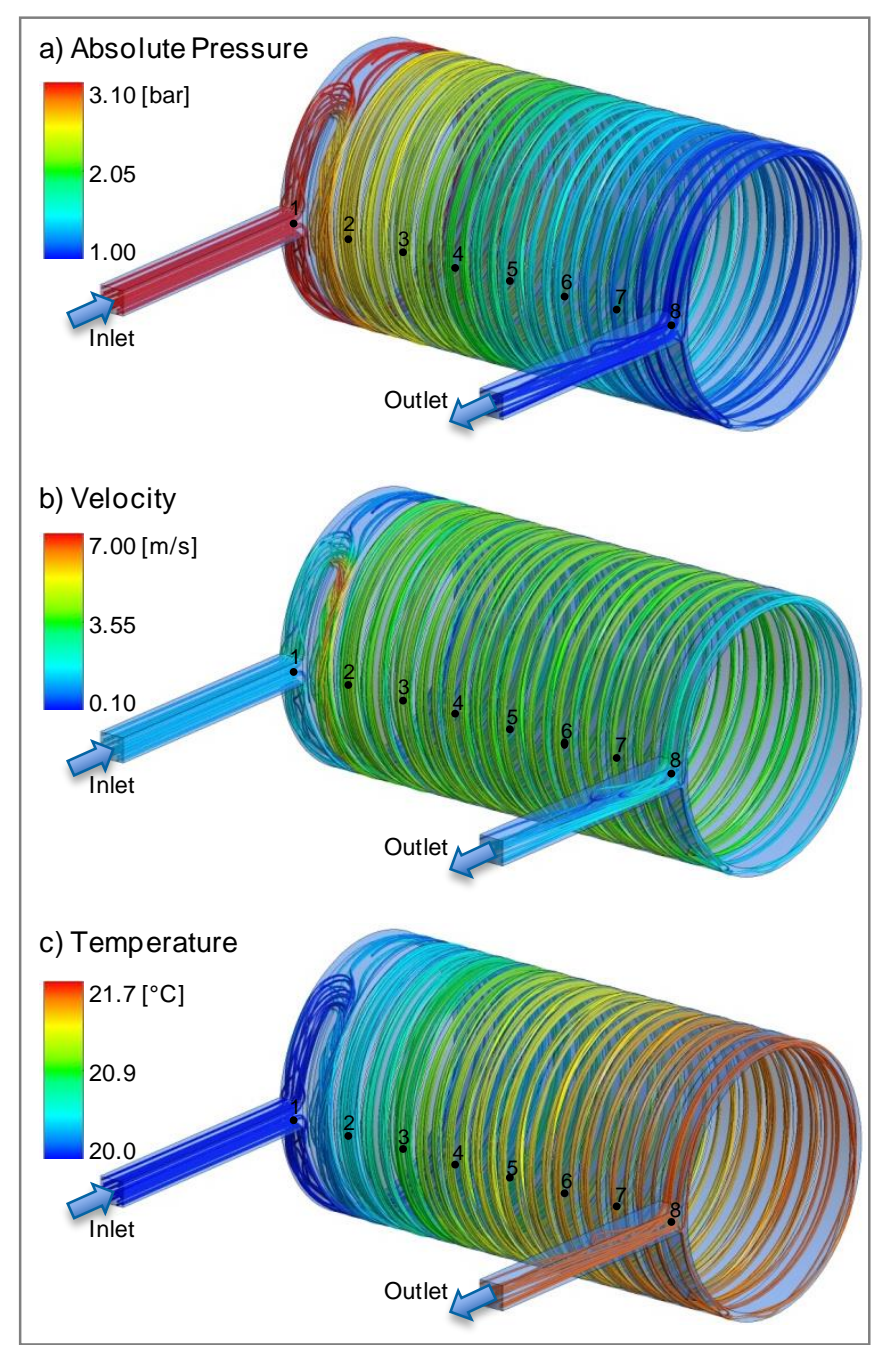

Figure 13: The pressure, velocity and temperature distribution along the fluids flow path with heating element temperature $T_{H}=40^{\circ} \mathrm{C}$ and flow rate $\dot{V}=14 \mathrm{l} / \mathrm{min}$.

Concerning fig. 14a one can see that the network-based modelling results of the single helical cooling channel are in good agreement with the numerical simulation as well as the experimental data. In the both upper diagrams of fig. 14a the relative deviations for the network-based model to the two other ones are depicted. The deviation amounts to a maximum of $2.4 \%$ compared with the experimental data and a maximum of $2.1 \%$ compared with the numerical simulation.

a)
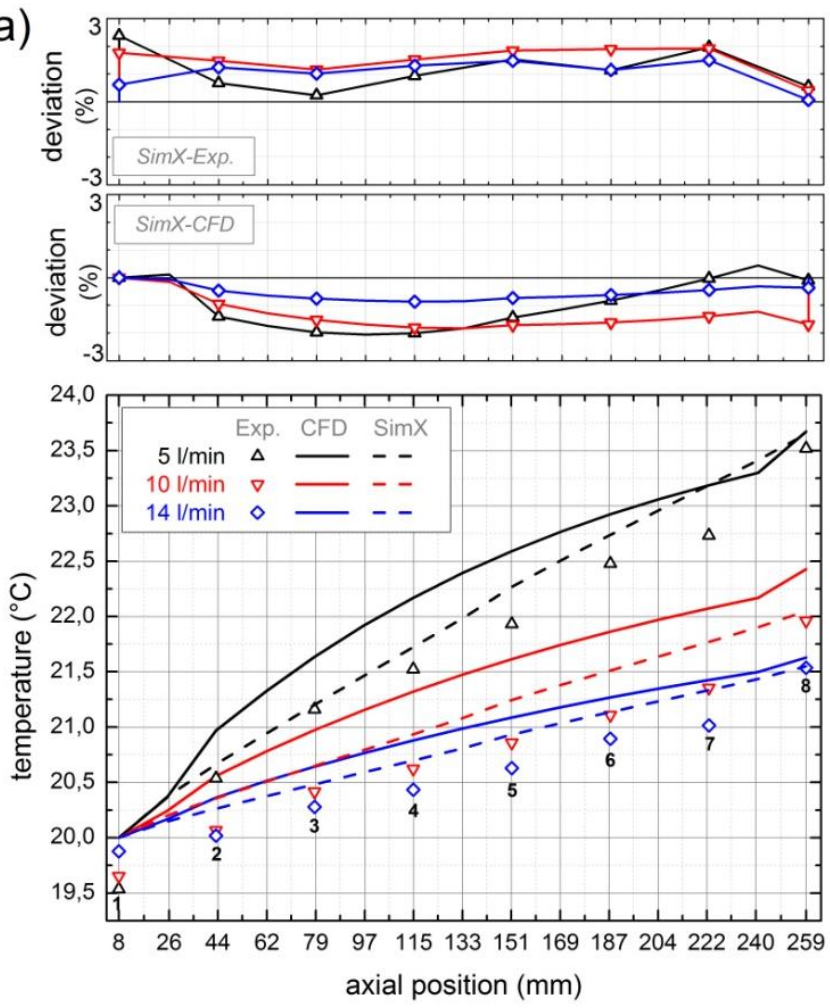

b)
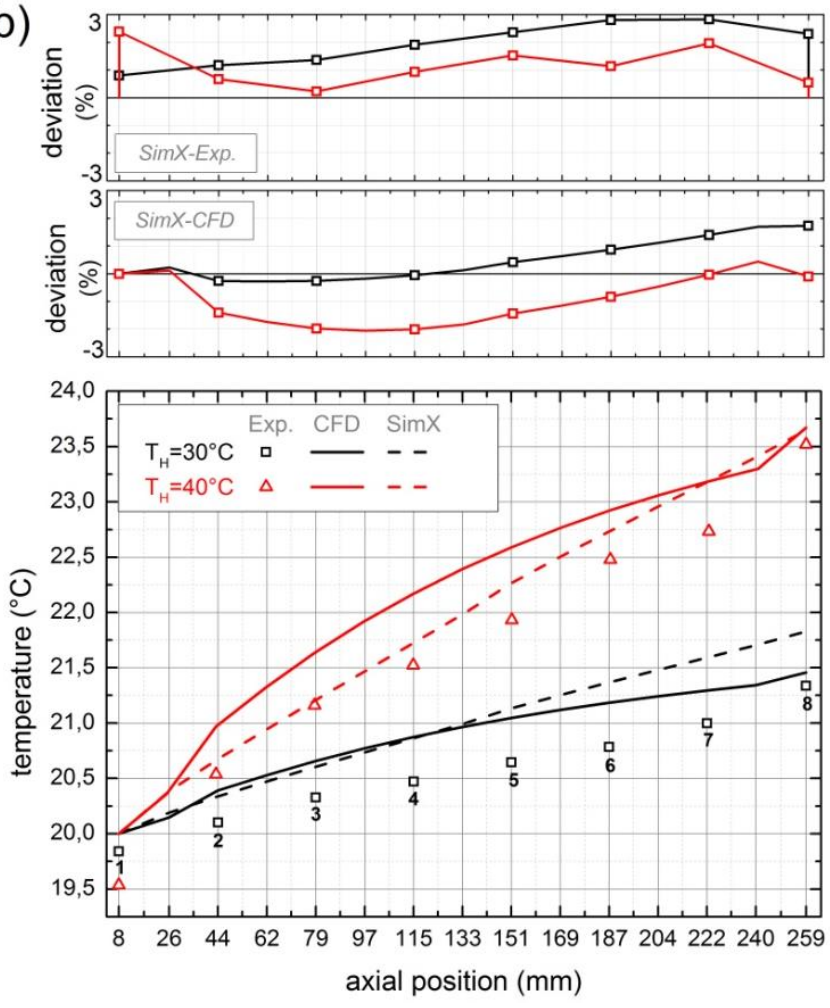

Figure 14: Simulation results showing the fluid warming along the spindle axis; a) with a constant heating element temperature $T_{H}=40^{\circ} \mathrm{C}$ concerning different volume flow rates; $b$ ) with a constant volume flow rate $\dot{V}=5 \mathrm{l} / \mathrm{min}$ concerning different heating element temperatures. 
The results in fig. 14b show the fluid warming in the axial direction with different heating element temperatures, $T_{H}=30^{\circ} \mathrm{C}$ and $40^{\circ} \mathrm{C}$, with a constant volume flow rate $\dot{V}=5 \mathrm{l} / \mathrm{min}$. It is observed that the fluid temperature increases with the heating temperature. Furthermore, the simulation results are in good agreement with the experimental and numerical data. The maximum deviation of the network-based results is about $2.8 \%$ (for a heating element temperature $T_{H}=30^{\circ} \mathrm{C}$ ) in comparison with the experimental data and about $2.1 \%$ (for $T_{H}=40^{\circ} \mathrm{C}$ ) in comparison with the numerical results.

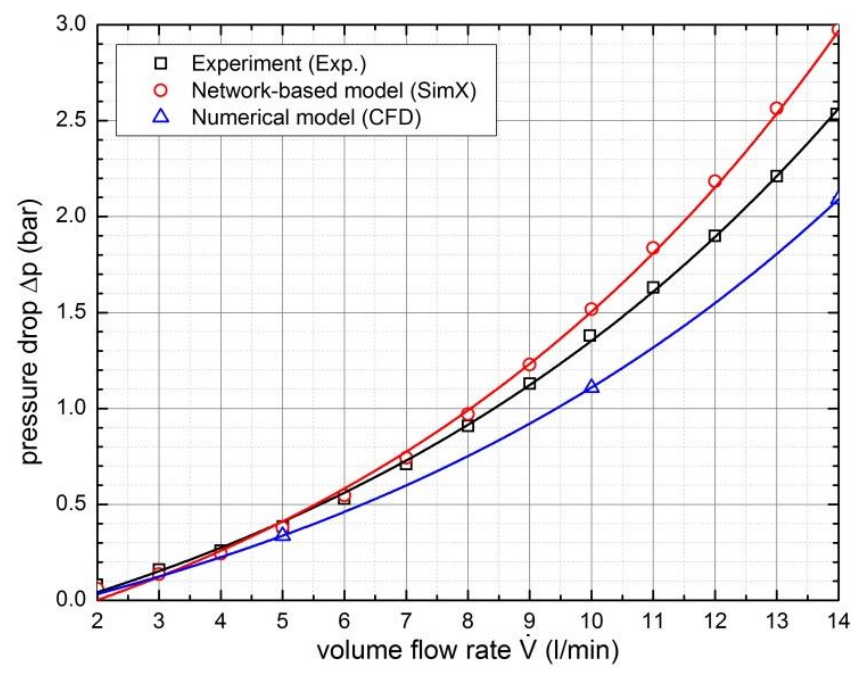

Figure 15: Pressure drop - flow rate characteristic, comparison between network-based model, numerical model and experimental data.

Figure 15 presents the calculated and measured pressure drop in the single helical cooling sleeve for varying volumetric flow rates from $21 / \mathrm{min}$ to $141 / \mathrm{min}$. It is seen that the simulated data are in good agreement with the measured ones. The error constantly rises with the volume flow rate to its maximum of about 0.5 bar. In case of the network-based model the calculated value exceeds the measured one. Whereas the numerical simulation model predicts a value of approximately 0.5 bar less for a volume flow rate of $14 \mathrm{l} / \mathrm{min}$. The reason for the smaller value in case of the numerical simulation is the simplification of the flow and return flow pipe. In case of the network-based model the causes for the deviations could not be conclusively clarified.

\section{Conclusion and outlook}

Especially in high-speed cutting applications heat dissipation and expansions of the spindle components have a negative impact on the manufacturing accuracy and quality. A selective control of the temperature distribution of a spindle is therefore a basic requirement for a high-precision machining. Thus, a network-based thermal model of heat transfer and fluid flow was developed to characterize the forced convection of cooling water within a single helical cooling channel of a high-speed spindle, and furthermore, to better control its temperature distribution and machining precision. Comparing a numerical with a network-based simulation model the second benefits from less modelling efforts and computing times. By combining network-based component models it is possible to develop complete system structures. This allows a precise description of the acting physical principles and interactions between the components at the system level. Furthermore integration into the machine control is conceivable in order to estimate or control the machines thermal behaviour.

Therefore, this paper explains a modelling approach enabling the computation of thermal and fluidic characteristics of the fluid within a single helical cooling sleeve of a motorized high-speed spindle. This modelling approach includes a numerical simulation and a networkbased simulation model as well. It is demonstrated that the averaged maximum temperatures along the spindle axis are decreased when the volume flow rates are increased. Furthermore the fluid temperature increases when the temperature of the heating element increases. The simulation results were validated through comparison with experimental data. It is shown that the network-based results agreed with the experimental data within $3 \%$ and with the numerical results, too. Concerning further investigations it is necessary to examine whether this deviations result from the simulation models or the experimental test set-up. Therefore, the accuracy of the chiller and the temperature sensors has to be improved, e.g. by the use of resistance thermometers instead of thermocouples.

However, the numerical simulation model can be extended by modelling the conjugate heat transfer $(\mathrm{CHT})$. Therefore the conduction equation is additionally solved within the numerical model.

$$
\frac{\partial(\rho h)}{\partial t}+\nabla\left(\rho U_{s} h\right)=\nabla(\lambda \nabla T)+S_{E}
$$

Considering the heat transfer in solid domains, especially for the cooling sleeve and the housing, is particularly advantageous for the parameterization of each heat transfer coefficient in the network-based model $[9,10]$.

\section{Acknowledgements}

The presented research activities are part of the Collaborative Research Centre Transregio 96 "Thermoenergetic design of machine tools. A systematic approach to solve the conflict between power efficiency, accuracy and productivity demonstrated at the example of machining production", sub-project A04 "Thermo-energetic description of fluid systems". The authors would like to thank the Deutsche Forschungsgemeinschaft (DFG, German Research Foundation) for the financial support.

\section{Supported by:}

\section{DFG $\begin{gathered}\text { Deursche } \\ \text { forschungssemenenschat }\end{gathered}$}




\section{Nomenclature}

\begin{tabular}{|c|c|c|}
\hline Designation & Denotation & Unit \\
\hline$C_{h}$ & Hydraulic capacity & {$\left[\mathrm{m}^{3} / \mathrm{Pa}\right]$} \\
\hline$C_{t}$ & Thermal capacity & {$[\mathrm{J} / \mathrm{K}]$} \\
\hline$d_{(o / i)}$ & (Outer/inner) Diameter & {$[\mathrm{mm}]$} \\
\hline$h_{(t o t)}$ & (Mean total) Enthalpy & {$[\mathrm{J} / \mathrm{kg}]$} \\
\hline$k$ & Turbulence kinetic energy & {$\left[\mathrm{m}^{2} / \mathrm{s}^{2}\right]$} \\
\hline$l$ & Length & {$[\mathrm{mm}]$} \\
\hline$m$ & Mass & {$[\mathrm{kg}]$} \\
\hline $\mathrm{Nu}$ & Nusselt number & {$[-]$} \\
\hline$p$ & Pressure & [bar] \\
\hline$P_{Q}$ & Cooling capacity & {$[\mathrm{W}]$} \\
\hline $\operatorname{Pr}$ & Prandtl number & {$[-]$} \\
\hline$Q$ & Heat quantity & {$[\mathrm{J}]$} \\
\hline$\dot{Q}$ & Heat/cooling in-/output & {$[\mathrm{W}]$} \\
\hline $\operatorname{Re}$ & Reynolds number & {$[-]$} \\
\hline$R_{h}$ & Hydraulic resistance & {$\left[\mathrm{Pa} /\left(\mathrm{m}^{3} \cdot \mathrm{s}\right)\right]$} \\
\hline$R_{t}$ & Thermal resistance & {$[\mathrm{K} / \mathrm{W}]$} \\
\hline$S_{E}$ & External energy source & {$[\mathrm{W}]$} \\
\hline$T$ & Temperature & {$\left[{ }^{\circ} \mathrm{C}\right]$} \\
\hline$t$ & Time & {$[\mathrm{s}]$} \\
\hline$T_{H}$ & Heating element temperature & {$\left[{ }^{\circ} \mathrm{C}\right]$} \\
\hline$U$ & Velocity & {$[\mathrm{m} / \mathrm{s}]$} \\
\hline$V$ & Volume & {$\left[\mathrm{m}^{3}\right]$} \\
\hline$\dot{V}$ & Volume flow rate & {$[1 / \min ]$} \\
\hline$\alpha_{(\text {alt })}$ & $\begin{array}{l}\text { (Alternative) Heat transfer } \\
\text { coefficient }\end{array}$ & {$\left[\mathrm{W} /\left(\mathrm{m}^{2} \cdot \mathrm{K}\right)\right]$} \\
\hline$\Delta p$ & Pressure drop/pressure loss & [bar] \\
\hline$\Delta T_{F}$ & Fluid temperature difference & {$[\mathrm{K}]$} \\
\hline$\varepsilon$ & Turbulence dissipation rate & {$\left[\mathrm{m}^{2} / \mathrm{s}^{3}\right]$} \\
\hline$\lambda$ & Thermal conductivity & {$\left[\mathrm{W} /\left(\mathrm{m}^{2} \cdot \mathrm{K}\right)\right]$} \\
\hline$v$ & Kinematic viscosity & {$[\mathrm{Pa} \cdot \mathrm{s}]$} \\
\hline$\rho$ & Density & {$\left[\mathrm{kg} / \mathrm{m}^{3}\right]$} \\
\hline$\tau$ & Wall shear stress & {$[\mathrm{MPa}]$} \\
\hline$\varphi$ & Angle & {$[\mathrm{rad}]$} \\
\hline$\omega$ & Specific turbulence dissipation & {$[1 / \mathrm{s}]$} \\
\hline
\end{tabular}

\section{References}

[1] R. Walter. Mit direkter Kühlung zu mehr Genauigkeit. Werkstatt und Betrieb, 139(6):129-130, 2006
[2] I. S. Javelov. Projektierung von Kühlsystemen für Elektrospindeln. Stanki i Instrument, 54(4):25-26, 1983.

[3] R. L. Judd, K. Aftab, M. A. Elbestawi. An Investigation of the Use of Heat Pipes for Machine Tool Spindle Bearing Cooling. International Journal of Machine Tools and Manufacture, 34(7): 1031-1043, 1994.

[4] K. Gebert. Ein Beitrag zur thermischen Modellbildung von schnelldrehenden Motorspindeln. Darmstädter Forschungsberichte für Konstruktion und Fertigung. Shaker Verlag, Aachen, 1997. ISBN 978-3-8265-28811.

[5] C. H. Chien, and J. Y. Jang. 3-D numerical and experimental analysis of a built-in motorized highspeed spindle with helical water cooling channel. Applied Thermal Engineering, 28: 2327-2336, 2008.

[6] J. Weber. Ein geräteorientiertes Modellierungskonzept mit Berücksichtigung der Fluideigenschaften für die dynamische Simulation in der Hydraulik. Dissertation, Technische Universität Dresden, 1990.

[7] E. Lautner, and F. Räpke. Simulationsmodul Fluidtechnik für systemübergreifende dynamische Analysen. Sonderdruck aus $\mathrm{O}+\mathrm{P}$ Ölhydraulik und Pneumatik, 41(6), 1997.

[8] G. Jungnickel. Simulation des thermischen Verhaltens von Werkzeugmaschinen. Modellierung und Parametrierung. Schriftenreihe des Lehrstuhls für Werkzeugmaschinen, Addprint AG, Dresden, 2010. ISBN 978-3-86780-172-0.

[9] ANSYS Inc. (ed.). ANSYS CFX-Solver Modeling Guide. Canonsburg, U.S.A., 2010.

[10] ANSYS Inc. (ed.). ANSYS CFX-Solver Theory Guide. Canonsburg, U.S.A., 2010.

[11]H. Sigloch. Technische Fluidmechanik. SpringerVerlag, Berlin, Heidelberg, 2009. ISBN 978-3-64203089-5.

[12] VDI (ed.). VDI-Wärmeatlas. Berechnungsunterlagen für Druckverlust, Wärme- und Stoffübertragung. Springer-Verlag, Berlin, Heidelberg, 2006. ISBN 3540255044.

[13]E. F. Schmidt. Wärmeübergang und Druckverlust in Rohrschlangen. Zeitschrift für Technische Chemie, Verfahrenstechnik und Apparatewesen, 39(13):781-832, 1967.

[14] J. Hak. Lösung eines Wärmequellen-Netzes mit Berücksichtigung der Kühlströme. Archiv für Elektrotechnik. 42(3):137-154, 1956 